\title{
Characterization of the isothermal solidification process in the Ni/Au-Ge layer system
}

\author{
Nico Weyrich ${ }^{1} \cdot$ Christian Leinenbach $^{1}$
}

Received: 14 January 2015 / Accepted: 4 March 2015/Published online: 11 March 2015

(C) Springer Science+Business Media New York 2015

\begin{abstract}
The eutectic Au28Ge (at.\%) solder alloy in combination with Ni substrates or Ni coatings is interesting for applications in transient liquid phase (TLP) bonding. To achieve sound joints with high re-melting temperatures, it is necessary to gain profound knowledge about the joining process. In this work, the isothermal solidification behavior in the $\mathrm{Ni}-\mathrm{Au} 28 \mathrm{Ge}$ (at.\%) system was analyzed by means of microstructure evolution and time to complete solidification. In short-time annealing experiments the early stage of the reaction $(<300 \mathrm{~s}$ over liquidus temperature) was investigated. It was observed that a continuous layer of $\mathrm{Ni}_{5} \mathrm{Ge}_{3}$ forms at the substrate-solder interface before scallop-like NiGe grains start to grow as solidification proceeds. Cyclic differential scanning calorimetry measurements were applied to estimate the time to complete solidification. Solidification was completed after less than $1 \mathrm{~h}$ in the $\mathrm{Ni}-\mathrm{Au} 28 \mathrm{Ge}$ (at.\%) system, which enables comparably short processing times for TLP bonding.
\end{abstract}

\section{Introduction}

For many applications joining by isothermal solidification of a liquid interlayer between two substrates has become an interesting alternative to processes like soldering or

Nico Weyrich

nico.weyrich@empa.ch

Christian Leinenbach

christian.leinenbach@empa.ch

1 Laboratory for Joining Technologies and Corrosion,

Empa - Swiss Federal Laboratories for Materials

Science and Technology, Überlandstrasse 129,

8600 Dübendorf, Switzerland brazing. This method is named transient liquid phase (TLP) bonding, diffusion soldering, or eutectic soldering. It makes use of metallic interlayers that melt at a certain temperature. Via interdiffusion between elements in the interlayer and base material, new phases with a higher melting point form during the joining process, leading to isothermal solidification $[1,2]$. The main advantage of TLP processes is that the re-melting temperature of the joints exceeds the initial bonding temperature. In addition to that, the microstructure and properties of the joints and the base material are often very similar. Processing can be done without high fixation pressures and at comparably low temperatures [1].

Depending on the application and the operation requirements, a wide range of substrate-interlayer combinations for TLP bonding was studied in the past [1]. X-Sn $(\mathrm{X}=\mathrm{Cu}, \mathrm{Ag}, \mathrm{Ni}, \mathrm{Au})$ systems, for example, have gained high technical and scientific interest for applications in microelectronics industry due to the fact that Sn offers a very low melting temperature of $232{ }^{\circ} \mathrm{C}$ [3]. For these configurations the formation of the joint is dominated by the diffusion of the base material into the liquid Sn layer. Isothermal solidification occurs by the formation of X-Sn intermetallic compounds with a higher melting point [3-7]. When Ni-based alloys are joined using $\mathrm{Ni}-\mathrm{B}, \mathrm{Ni}-\mathrm{Cr}-\mathrm{B}$ or multicomponent $\mathrm{Ni}-\mathrm{Cr}-\mathrm{B}-\mathrm{Fe}-\mathrm{Si}$ filler alloys [8-10], fast diffusing melting point depressing elements like B diffuse into the base material, leading to a change of composition within the gap. Thus, the melting temperature of the filler alloy increases, thereby causing isothermal solidification.

Refractory metals are often used for the so called partial transient liquid phase bonding (PTLP) of ceramic materials. A low melting metal (e.g., $\mathrm{Cu}$ ) is deposited onto a much thicker layer of a refractory metal with a very high melting point (e.g., $\mathrm{Mo}, \mathrm{Nb}$ ). At joining temperature the 
low melting material melts while simultaneously wetting the ceramic surface and diffusing into the refractory core $[1,11-13]$. Disadvantages of this technique are the usually high temperatures $\left(>1000{ }^{\circ} \mathrm{C}\right)$. Depending on the material selection typically long processing times (around $6 \mathrm{~h}$ ) are required to complete the joining process. In a previous work of the present authors, $\mathrm{Al}_{2} \mathrm{O}_{3}$ ceramic plates could be successfully joined using eutectic $\mathrm{Au}-(\mathrm{Ge}, \mathrm{Si})$ solder alloys in combination with a multilayer coating ( $\mathrm{Ti}-\mathrm{W}-\mathrm{Ni})$ on the ceramics $[14,15]$. Ge and $\mathrm{Si}$ react with the $\mathrm{Ni}$ wetting layer at a low joining temperature of $400{ }^{\circ} \mathrm{C}$ and $10 \mathrm{~min}$ dwell time to form intermetallic phases at the solder-substrate interface, leaving an Au-rich layer in the center of the joint gap. Due to that reaction isothermal solidification takes place and the re-melting temperature of the joints exceeds the initial process temperature significantly [15].

For all the possible material combinations in TLP bonding the formation of a sound joint relies on the full consumption of the low melting interlayer material and the formation of intermetallic compounds or solid solutions with a higher melting point. Therefore, profound knowledge about the reactions and the reaction kinetics during the process is necessary. Several authors have already reported on the experimental study of the kinetics in TLP bonding using differential scanning calorimetry (DSC). Venkatraman et al. investigated the interaction of electroplated $\mathrm{Au}$ and $\mathrm{Sn}$ on $\mathrm{Cu}$ substrates via DSC analysis [16]. The authors annealed the samples above the Au-Sn eutectic temperature for different holding times and measured the melting and solidification enthalpies, respectively. By introducing the enthalpy as a measure for the (remaining) liquid in the system they were able to follow the solidification process and estimate the time for the completion of isothermal solidification. A comparable research approach was applied in the work of Kuntz and Corbin who studied the $\mathrm{Pb}-\mathrm{Sn}$ and $\mathrm{Ag}-\mathrm{Cu}$ system [17-20]. By customizing the temperature profile of the measurements, it was possible to deal with a base line shift that occurred during the first temperature cycle and was assumed to be due to a change in thermal contact resistance. In the $\mathrm{Ag}-\mathrm{Cu}$ system primary solidification during cooling was found which is not visible in the DSC signal. Thus, a mathematical correction factor was introduced to prevent an underestimation of the fraction of remaining liquid $[18,19]$. Li et al. analyzed the $\mathrm{Ag}-$ $\mathrm{Sn}-\mathrm{Ag}$ layer system with the help of isothermal as well as cyclic DSC tests [6]. The fraction of remaining liquid Sn was approximated by calculating the ratio of solidification exotherm and melting endotherm and the growth rate of the $\mathrm{Ag}_{3} \mathrm{Sn}$ phase was derived.

The aim of the current work was to study the isothermal solidification behavior in the $\mathrm{Ni}-\mathrm{Au} 28 \mathrm{Ge}$ (at.\%) system. A DSC method based on the above-mentioned techniques was developed which enables the estimation of the time needed for complete isothermal solidification in TLP bonding. In addition to that the early stage of the solidification was investigated and the mechanism of intermetallics' (IMC) growth and solidification was deduced. The special focus was on TLP bonding using a eutectic Au28Ge (at.\%) interlayer between $\mathrm{Ni}$ substrates. This system has already been analyzed with respect to wetting behavior, microstructure, and bond strength in our earlier work $[6,14,15]$.

\section{Materials and experimental methods}

\section{Materials and specimen preparation}

Specially designed Ni crucibles with an inner diameter of $5.6 \mathrm{~mm}$ and corresponding lids (diameter $5.4 \mathrm{~mm}$ ) were machined from commercially pure Ni (Nickel 200/201) rods (Bibus Metals AG, Fehraltorf, Switzerland). A 25- $\mu \mathrm{m}$ thick eutectic Au28Ge (at.\%) solder foil with a melting temperature of $361{ }^{\circ} \mathrm{C}$ was produced by Materion Advanced Materials Technologies and Services, Hungerford, UK. All materials were carefully cleaned in distilled water and high purity acetone prior to the experiments. The foil was placed inside the crucible with a lid on top (Fig. 1). Afterwards, the assembly was pressed in a hydraulic press with a pressure of approximately 2.5 tons to ensure an intimate contact between the components. This procedure did not lead to significant plastic deformation of the crucible. Samples prepared in that way were used for DSC tests as well as for short-term annealing tests.

\section{Differential scanning calorimetry (DSC)}

\section{Test setup}

The DSC experiments were carried out using a Netzsch DSC 404 F3 Pegasus (Netzsch, Selb Germany). Preliminary tests with the Au28Ge (at.\%) alloy were done in a standard $\mathrm{Al}_{2} \mathrm{O}_{3}$ crucible to study the thermal behavior of the alloy without any metallurgical reaction with the $\mathrm{Ni}$ crucible. The system was heated up with a heating rate of $10 \mathrm{~K} \mathrm{~min}^{-1}$ to a maximum temperature of $400{ }^{\circ} \mathrm{C}$, which

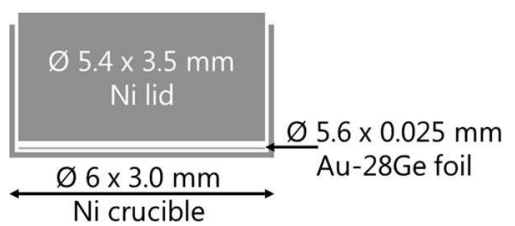

Fig. 1 Schematic of the sample setup for DSC test and short-time annealing 
is well above the liquidus temperature of the alloy, and was cooled down immediately.

In Fig. 2 a representative DSC signal of the pure solder alloy in an alumina crucible is shown. As expected, the alloy melts at the eutectic temperature of $361{ }^{\circ} \mathrm{C}$. When cooling down, significant undercooling was detected and solidification occurred at approximately $340{ }^{\circ} \mathrm{C}$. During heating and cooling no other thermal events besides the melting and freezing, respectively, were detected.

In a second step, cyclic DSC experiments were carried out using the Ni crucibles. Temperature was cycled between $T_{\min }$ and $T_{\max }$ with different dwell times $t_{\text {dwell }}$ (Fig. 3). $T_{\max }$ was set to $400{ }^{\circ} \mathrm{C}$ to allow the DSC signal to return to the baseline before reaching the isothermal section. $T_{\min }$ was set to $280^{\circ} \mathrm{C}$, i.e., considerably below the temperature of undercooling of the alloy to allow complete solidification. The dwell time was varied between 0,5 , or 8 min, whereas within each DSC run the dwell time was kept constant. Heating and cooling rates were set to $10 \mathrm{~K} \mathrm{~min}^{-1}$ in all test.

\section{Data evaluation}

In earlier studies the $\mathrm{Ni}-\mathrm{Au} 28 \mathrm{Ge}$ (at.\%) layer system was analyzed with respect to the evolving microstructure during joining $[15,21]$. It was shown that the intermetallic phases $\mathrm{NiGe}$ and $\mathrm{Ni}_{5} \mathrm{Ge}_{3}$ form at $400{ }^{\circ} \mathrm{C}$. While the eutectic structure of the solder alloy vanished completely, an $\mathrm{Au}-$ rich layer in the center of the joints occurred. No ternary compounds were observed which is in agreement with the $\mathrm{Au}-\mathrm{Ge}-\mathrm{Ni}$ phase diagram reported in [22]. In that work, it was found that no ternary compound exists up to $600{ }^{\circ} \mathrm{C}$. In addition to that, the liquid Au28Ge (at.\%) exhibits no pronounced solubility for $\mathrm{Ni}$ as can be seen in the isothermal section of the ternary phase diagram at $400{ }^{\circ} \mathrm{C}$

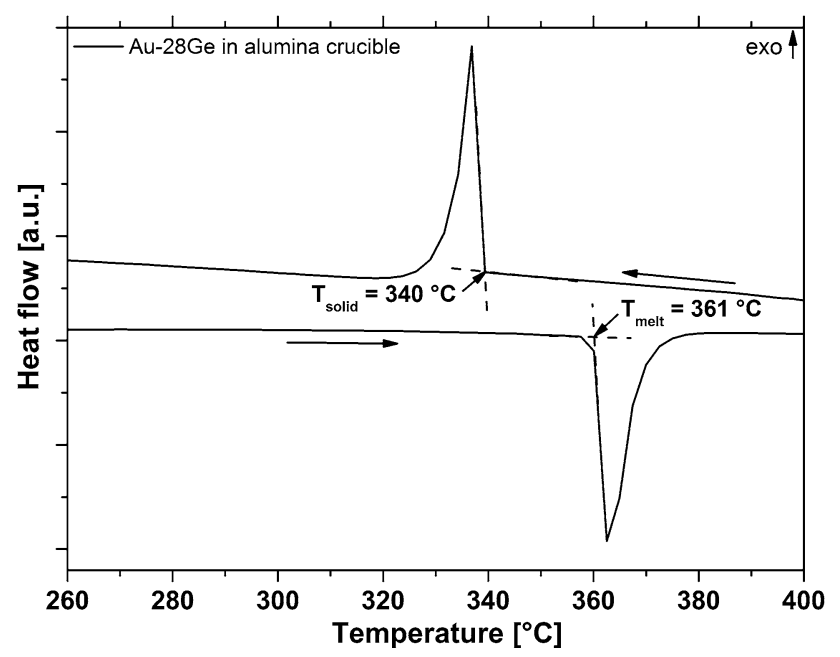

Fig. 2 DSC measurement of Au28Ge (at.\%) in an alumina crucible

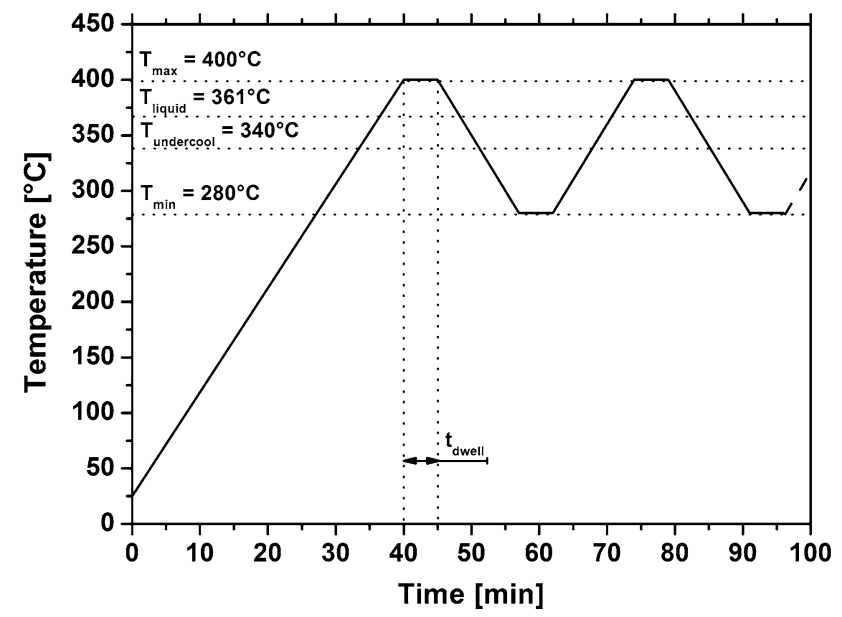

Fig. 3 Section of the temperature-time profile for the cyclic DSC tests

shown in Fig. 4a. From these findings it can be concluded that only the binary phase diagrams Au-Ge (cf. Fig. 4b) and $\mathrm{Ni}-\mathrm{Ge}$ (cf. Fig. 4c) have to be taken into consideration for the analysis of the Ni-Au28Ge (at.\%) TLP bonding system. For the evaluation of the DSC data the following assumptions were made:

1. Mass conservation of Au28Ge (at.\%) in the system. The melt fully remains in the joining gap between the $\mathrm{Ni}$ crucible and the lid during the DSC tests.

2. No solubility of $\mathrm{Ni}$ in liquid Au28Ge (at.\%). The composition of the liquid phase was fixed at Au28Ge (at.\%) at $400{ }^{\circ} \mathrm{C}$.

3. The solubility of $\mathrm{Ge}$ in $\mathrm{Au}$ at $400{ }^{\circ} \mathrm{C}$ was set to 2.8 at.\% according to the phase diagram in Fig. $4 \mathrm{~b}$.

4. Negligible diffusion of $\mathrm{Ge}$ into Ni. A low interdiffusion coefficient for $\mathrm{Ge}$ in $\mathrm{Ni}\left(D \approx 10^{-24} \mathrm{~m}^{2} \mathrm{~s}^{-1}\right)$ at $400{ }^{\circ} \mathrm{C}$ can be calculated according to $[24,25]$. In addition to that, a large driving force for the formation of the intermetallic phases $\mathrm{Ni}_{5} \mathrm{Ge}_{3}$ and $\mathrm{NiGe}$ was reported in [22]. Thus, it is assumed that all Ge fully reacts with $\mathrm{Ni}$ to form the IMCs.

The reaction of Ni with Ge leads to a decrease of the Ge amount in the interlayer. Consequently, the overall alloy composition deviates from the eutectic composition and therefore the fraction of liquid in the system decreases. To quantify the amount of the remaining liquid phase in the system the melting enthalpies $\left(\Delta H_{\mathrm{m}, \mathrm{n}}\right)$ for each cycle were calculated by integrating the area under the endotherm melting peak in the DSC signal as shown in Fig. 5. For the integration a linear base line correction was applied.

The initial melting enthalpy $\left(\Delta H_{\mathrm{m}, 0}\right)$ was used as a reference and set equal to $100 \%$ liquid. During the first heating cycle the whole interlayer melts, since the alloy exhibits a homogeneous eutectic structure. With every 


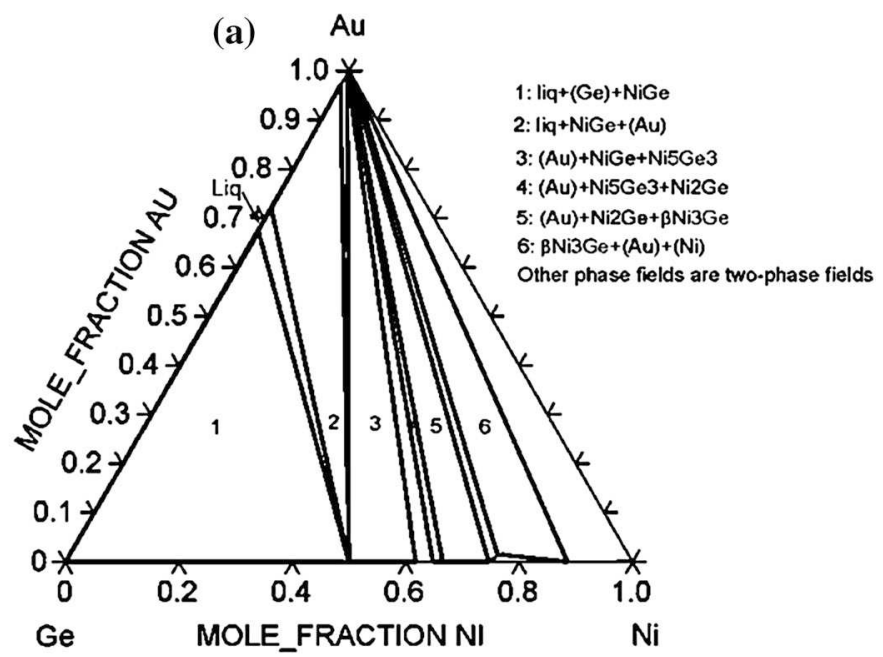

(b) Weight Percent Germanium

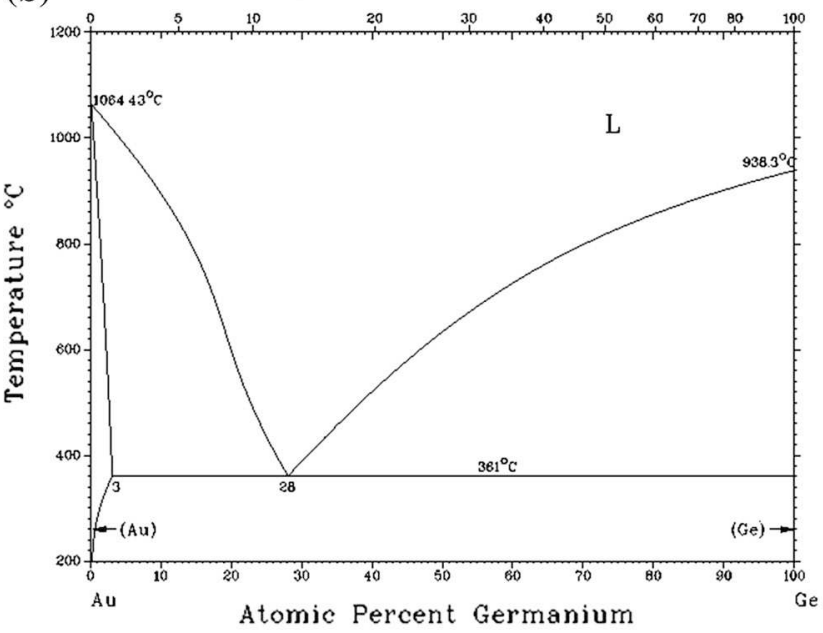

(c)

Weight Percent Germanium

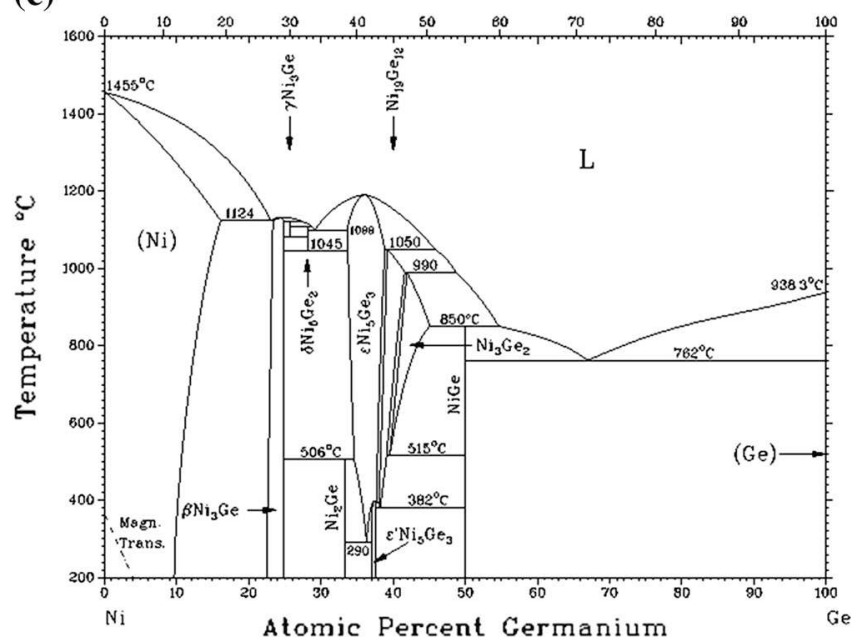

Fig. 4 a Isothermal section of the $\mathrm{Au}-\mathrm{Ge}-\mathrm{Ni}$ phase diagram at $400{ }^{\circ} \mathrm{C}$; binary phase diagrams of $\mathbf{b}$ Au-Ge [23], and $\mathbf{c}$ Ni-Ge [23] (Reprinted with permission of ASM International)

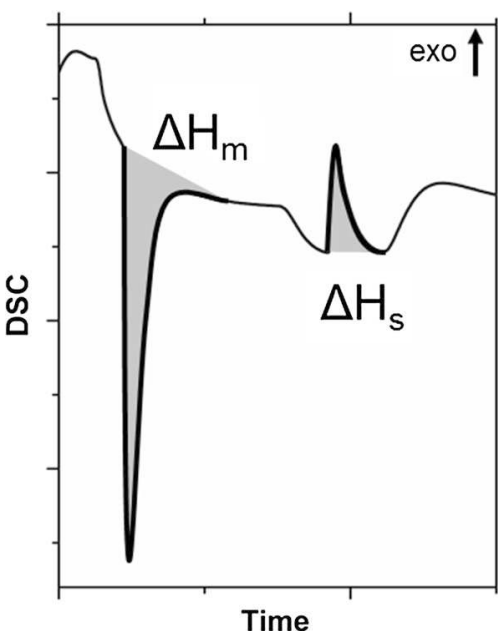

Fig. 5 Heat flow over time scheme for a single DSC cycle including enthalpy calculation additional cycle the melting (and solidification) enthalpies decrease due to the reaction of $\mathrm{Ge}$ with $\mathrm{Ni}$. By referring the melting enthalpies in every cycle $n\left(\Delta H_{\mathrm{m}, \mathrm{n}} ; n \neq 0\right)$ to the initial melting enthalpy $\left(\Delta H_{\mathrm{m}, 0}\right)$ the fraction of liquid ( $\left.f_{\text {liquid,n }}\right)$ within the system is:

$f_{\text {liquid, } \mathrm{n}}=\Delta H_{\mathrm{m}, \mathrm{n}} / \Delta H_{\mathrm{m}, 0}$

The estimation of the time needed for complete isothermal solidification was made based on the calculation of the fraction of liquid in the system. Complete solidification was assumed when the fraction of liquid was smaller than $1 \%$.

\section{Short term annealing and metallography}

To investigate the microstructure evolution during the early stage of solidification an experimental setup comparable to 
the one described in [3] was applied. A partly open cavity was manufactured from $\mathrm{Cu}$ bulk material and connected to a thermocouple (Fig. 6). This $\mathrm{Cu}$ cavity was put into an airfurnace at a temperature of $400{ }^{\circ} \mathrm{C}$. The test samples were annealed in the $\mathrm{Cu}$ cavity for different holding times between 30 and $300 \mathrm{~s}$. Finite element simulations showed that the whole crucible reached a homogeneous temperature of $400{ }^{\circ} \mathrm{C}$ within $2 \mathrm{~s}$ and therefore, the heating step was neglected in the further analysis. After annealing the specimens were cooled to ambient temperature on air. For the microstructural investigation they were cut in two halves and metallographic cross sections were prepared. The cross sections were studied via scanning electron microscope (SEM, FEI ESEM XL 30, Eindhoven, Netherlands) equipped with an energy dispersive X-ray (EDX, EDAX XL 30, USA) detector for semi-quantitative analysis.

\section{Results}

\section{Cyclic DSC tests}

To determine the time required for the completion of solidification and to derive the concentration change within the soldering gap during the joining process cyclic DSC tests were carried out. A representative DSC signal as a function of time during a cyclic test is plotted in Fig. 7. Well distinct melting $\left(\Delta H_{\mathrm{m}, \mathrm{n}}\right)$ and solidification $\left(\Delta H_{\mathrm{s}, \mathrm{n}}\right)$ reactions can be observed during each cycle. The bumps between the solidification exotherm and the next melting endotherm are baseline shifts due to the conversion of the heating rate.

As can be clearly seen in Fig. 7 the melting and solidification enthalpies become smaller after each temperature cycle. Consequently, it follows that solidification proceeds and the fraction of liquid decreases. Some Ge of the Au28Ge (at.\%) solder alloy reacts with $\mathrm{Ni}$ to form intermetallic phases and the composition in the soldering gap changes. Only the areas with the eutectic composition become liquid during the next heating segment resulting in $\Delta H_{\mathrm{m}, \mathrm{n}}<\Delta H_{\mathrm{m}, \mathrm{n}+1}$. For each cycle $\mathrm{n}$ the melting enthalpy is bigger than the solidification enthalpy, which indicates a pronounced reaction between $\mathrm{Ge}$ and $\mathrm{Ni}$ during a single

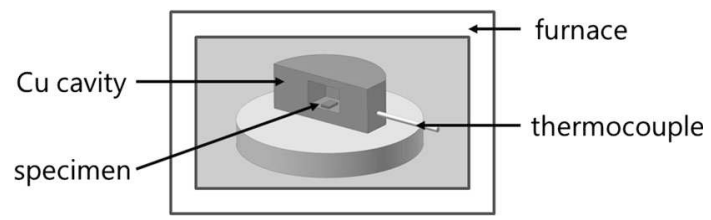

Fig. 6 Experimental setup for short-time annealing

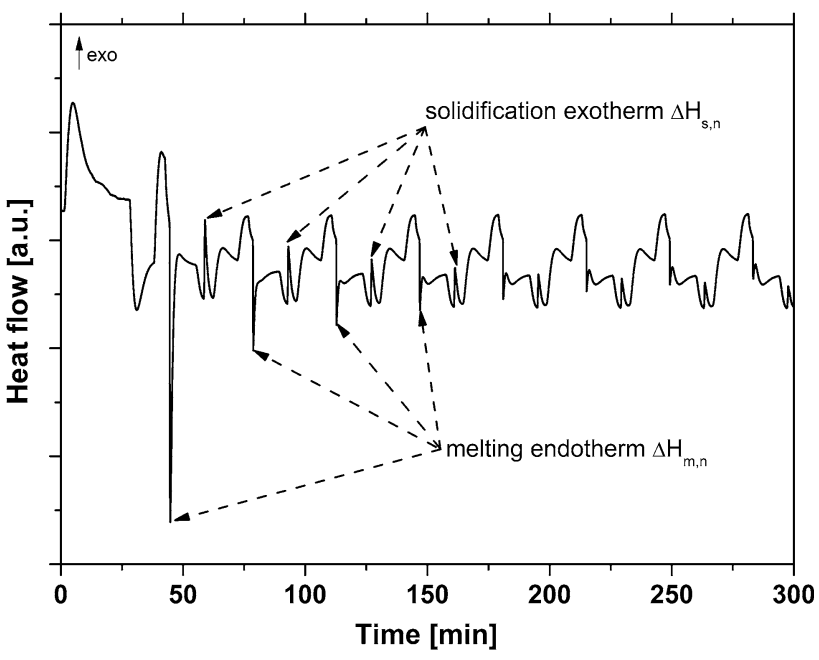

Fig. 7 Heat flow over time of a cyclic DSC measurement

cycle. This is because isothermal solidification due the formation of Ni-Ge intermetallics is not directly visible in the DSC signal and therefore, only the solidification of the remaining liquid is recorded during cooling, leading to $\Delta H_{\mathrm{m}, \mathrm{n}}>\Delta H_{\mathrm{s}, \mathrm{n}}$.

Figure 8 shows the change of the fraction of liquid as a function of time over liquidus during the cyclic DSC tests without any dwell time and with a dwell time of 5 and $8 \mathrm{~min}$ at $400{ }^{\circ} \mathrm{C}$, respectively. The fraction of liquid was calculated according to Eq. (1) while the time over liquidus $\left(t_{\text {over liquid }}\right)$ results from:

$t_{\text {overliquid }}=t_{\text {heat }}+t_{\text {dwell }}+t_{\text {cool, }}$

where $t_{\text {heat }}$ is the time required for heating from the liquidus temperature of $361{ }^{\circ} \mathrm{C}$ to the final temperature of $400{ }^{\circ} \mathrm{C}, t_{\mathrm{dwell}}$ is the dwell time and $t_{\text {cool }}$ is the cooling period from $400{ }^{\circ} \mathrm{C}$ to below the undercooling temperature of $340{ }^{\circ} \mathrm{C}$.

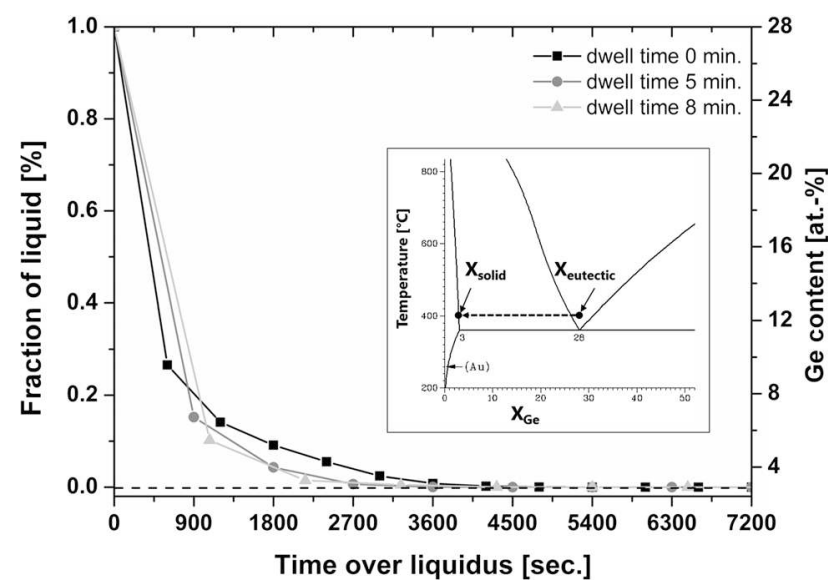

Fig. 8 Change in the fraction of liquid and Ge content over time; inset: concentration change in $\mathrm{Au}-\mathrm{Ge}$ phase diagram 
When the eutectic temperature is reached for the first time at $t_{\text {over liquid }}=0$, the whole Au28Ge (at.\%) interlayer melts and in this case the fraction of liquid is $100 \%$. After the first temperature cycle the fraction of liquid decreases rapidly. As can be seen in Fig. 8 the amount of liquid reduces to only $26 \%$ after simply heating and cooling, i.e., without any dwell time. For 5 and $8 \mathrm{~min}$ dwell time at $400{ }^{\circ} \mathrm{C}$ the fraction of liquid is 15 and $10 \%$, respectively, after the first cycle. At $t_{\text {over liquid }}=1800 \mathrm{~s}$ the fraction of liquid reduced to $9 \%$ for the tests without any dwell time and to $4 \%$ for the tests with a dwell time of $5 \mathrm{~min}$ at $400{ }^{\circ} \mathrm{C}$. Comparing these two values, it can be assumed that the IMC formation is more pronounced if the specimens are kept at $400{ }^{\circ} \mathrm{C}$ for a longer time, which results in different times to complete solidification: Solidification is completed after approximately $2200 \mathrm{~s}$ when a dwell time of $8 \mathrm{~min}$ is used. Decreasing the dwell time at $400{ }^{\circ} \mathrm{C}$ to $5 \mathrm{~min}$ led to an increase of the time required for the completion of solidification to approximately $2700 \mathrm{~s}$. In the experiments without any dwell time solidification was completed after $3600 \mathrm{~s}$.

From the fraction of liquid in the system the concentration change of $\mathrm{Ge}\left(X_{\mathrm{Ge}, \mathrm{n}}\right)$ in the joint gap can be derived by applying the lever rule for phase diagrams:

$X_{\mathrm{Ge}, \mathrm{n}}=f_{\text {liquid, } \mathrm{n}} \times\left(X_{\text {eutectic }}-X_{\text {solid }}\right)+X_{\text {solid }}$

$f_{\text {liquid,n }}$ represents the fraction of liquid calculated by Eq. (1). The eutectic composition $\left(X_{\text {eutectic }}=28\right.$ at. $\left.\% \mathrm{Ge}\right)$ and the composition of the Au-Ge solid solution $\left(X_{\text {solid }}=2.8\right.$ at. $\left.\% \mathrm{Ge}\right)$ at $400{ }^{\circ} \mathrm{C}$ are taken from the binary phase diagram.

Figure 8 also shows the change in the composition of the joint gap over time. Starting from the eutectic composition at 28 at.\% of $\mathrm{Ge}$ the concentration decreases rapidly during the first cycle, i.e., during 900 s, to less than 8 at.\%. The Ge consumption rate decreases afterwards. When solidification is completed after $3600 \mathrm{~s}$ the composition of the $\mathrm{Au}-\mathrm{Ge}$ solid solution $\left(X_{\mathrm{Ge}}=2.8\right.$ at.\%) is reached. This concentration change can also be drawn in the $\mathrm{Au}-\mathrm{Ge}$ phase diagram. Starting from the eutectic composition $\left(X_{\text {eutectic }}\right)$ the change in Ge content follows the dotted arrow which represents an isothermal line at $400{ }^{\circ} \mathrm{C}$ (inset Fig. 8).

\section{Early stage reactions}

The rapid isothermal solidification observed in the cyclic DSC tests indicates that a strong reaction occurs during the first cycle, i.e., during the first $900 \mathrm{~s}$ of the joining process, leading to a pronounced consumption of Ge. To follow the solidification process and the microstructure evolution during this early stage of the reaction, short-term annealing experiments were carried out. The micrograph in Fig. 9a
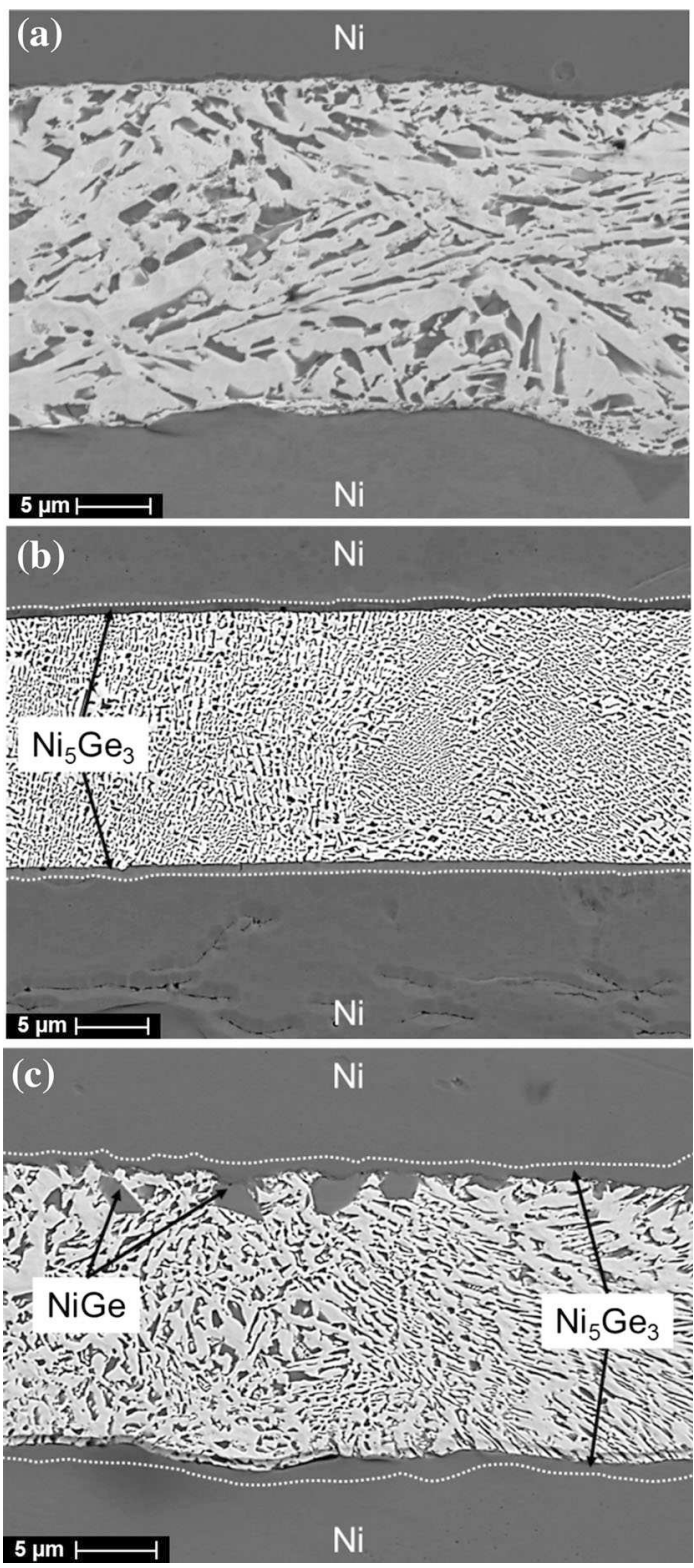

Fig. 9 Microstructure evolution in $\mathrm{Ni}-\mathrm{Au} 28 \mathrm{Ge}-\mathrm{Ni}$ joints after a assembly (0 s annealing), b $60 \mathrm{~s}$ at $400{ }^{\circ} \mathrm{C}$, and c $120 \mathrm{~s}$ at $400{ }^{\circ} \mathrm{C}$

shows the initial assembly with the Au28Ge (at.\%) solder foil sandwiched in between the Ni substrates. In the initial state no reactions have taken place and the $\mathrm{Au}-\mathrm{Ge}$ foil is characterized by a homogeneous eutectic microstructure. The average gap width in this case was measured to $22.5 \mu \mathrm{m}$. After $60 \mathrm{~s}$ at $400{ }^{\circ} \mathrm{C}$ the formation of $\mathrm{Ni}_{5} \mathrm{Ge}_{3}$ was observed. As can be seen in Fig. 9b, a continuous layer of $\mathrm{Ni}_{5} \mathrm{Ge}_{3}$ with an average thickness of $0.6 \pm 0.11 \mu \mathrm{m}$ formed at both $\mathrm{Ni}-\mathrm{Au} 28 \mathrm{Ge}$ (at.\%) interfaces. The dotted lines in Fig. $9 \mathrm{~b}$ indicate the interface between $\mathrm{Ni}_{5} \mathrm{Ge}_{3}$ and the Ni substrate. It is remarkable that the amount of $\mathrm{Ge}$ grains within the eutectic structure increased while their average size significantly decreased. Most likely this is due 
to the fact that the solder foils were produced by splat quenching which results in a non-equilibrium structure. After short-time annealing the samples were cooled on air which leads to a much lower cooling rate and the different grain size of the eutectic structure. After $120 \mathrm{~s}$ at $400{ }^{\circ} \mathrm{C}$ discontinuous and scallop-like $\mathrm{NiGe}$ grains appeared at the interface between the Au28Ge (at.\%) layer and $\mathrm{Ni}_{5} \mathrm{Ge}_{3}$ (Fig. 9c). The thickness of the $\mathrm{Ni}_{5} \mathrm{Ge}_{3}$ layer increased slightly to an average of $0.9 \pm 0.1 \mu \mathrm{m}$. Already in that state of the reaction, areas enriched in Au were detected.

Figure 10a shows the joint microstructure after annealing for $180 \mathrm{~s}$ at $400{ }^{\circ} \mathrm{C}$. Compared to the previous state
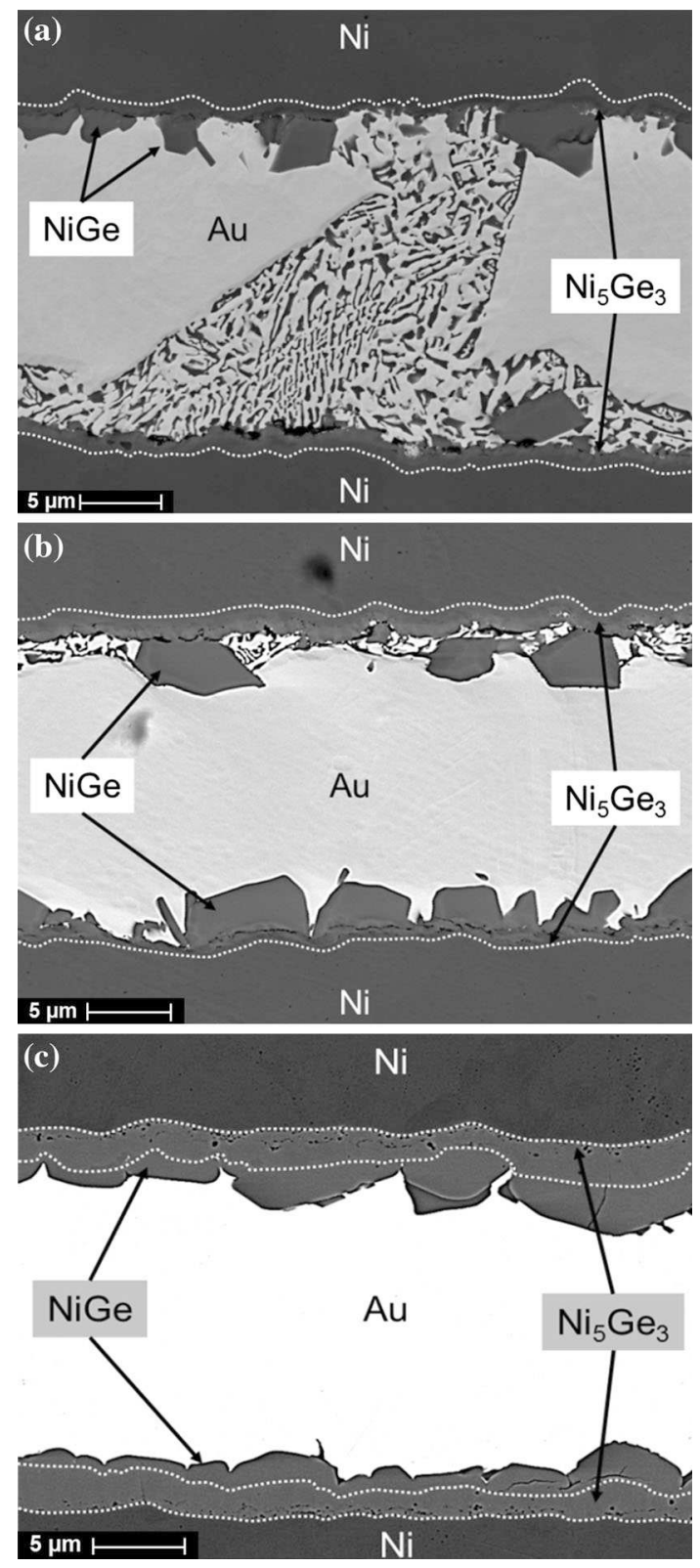

Fig. 10 Microstructure evolution in $\mathrm{Ni}-\mathrm{Au} 28 \mathrm{Ge}-\mathrm{Ni}$ joints a after $180 \mathrm{~s}$ at $400{ }^{\circ} \mathrm{C}, \mathbf{b}$ after $300 \mathrm{~s}$ at $400{ }^{\circ} \mathrm{C}$, and $\mathbf{c}$ at the final state $(1 \mathrm{~h})$
(Fig. 9c) more and larger NiGe grains next to the $\mathrm{Ni}_{5} \mathrm{Ge}_{3}$ layer were detected. In addition, the thickness of the $\mathrm{Ni}_{5-}$ $\mathrm{Ge}_{3}$ layer increased to $1.3 \pm 0.23 \mu \mathrm{m}$. Furthermore, large areas with a composition of almost 100 at.\% Au were observed. With the growth of these Au-rich areas the fraction of the remaining liquid in the joint gap strongly decreased. The Au-rich regions expanded and enclosed the eutectic melt in between. After $300 \mathrm{~s}$ at $400{ }^{\circ} \mathrm{C}$ the eutectic structure of the solder alloy vanished almost completely. As can be seen in Fig. 10b, only small areas with eutectic structure, most of them adjacent to the IMC interface, were found in between the NiGe grains. The number of NiGe grains increased as well as their size. In addition to that, further growth of the $\mathrm{Ni}_{5} \mathrm{Ge}_{3}$ layer (thickness $\approx 1.7 \pm 0.2 \mu \mathrm{m}$ ) was observed. At this stage of the reaction the main fraction of the joint gap consists of an almost pure $\mathrm{Au}$ phase. The microstructure after heat treatment at $400{ }^{\circ} \mathrm{C}$ for $1 \mathrm{~h}$ is shown in Fig. 10c. On both sides of the joint next to the Ni substrates continuous layers of $\mathrm{Ni}_{5} \mathrm{Ge}_{3}$ were detected with an average thickness of $1.9 \pm 0.4 \mu \mathrm{m}$. Adjacent to the $\mathrm{Ni}_{5} \mathrm{Ge}_{3}$ phase an almost continuous layer of NiGe grains with a scallop-like structure and a thickness between 1 and $2 \mu \mathrm{m}$ was found. The center of the joint gap consists of almost pure Au and the eutectic structure has completely disappeared.

\section{Discussion}

\section{Isothermal solidification process}

The cyclic DSC tests in combination with the short-term annealing tests showed that the Au28Ge (at.\%) solder solidifies rapidly at isothermal holding temperatures above the liquidus of the solder alloy when in contact with $\mathrm{Ni}$ substrates. This is due to pronounced reaction of Ge from the molten solder with the solid $\mathrm{Ni}$. It leads to the formation of $\mathrm{Ni}_{5} \mathrm{Ge}_{3}$ and NiGe IMCs at the interface between the solder and the Ni substrate as well as Au solid solution in the joint gap. According to the work of Jin et al. [26], both the $\mathrm{Ni}_{5} \mathrm{Ge}_{3}$ and the $\mathrm{NiGe}$ phase have very negative free energies of formation $\left(\mathrm{Ni}_{5} \mathrm{Ge}_{3}:-37 \mathrm{~kJ} \mathrm{~mol}^{-1}\right.$, NiGe: $-34.9 \mathrm{~kJ} \mathrm{~mol}^{-1}$ ) and large driving forces for formation. When the solder alloy liquefies it is likely that a certain amount of $\mathrm{Ni}$ is dissolved in the solder in the vicinity of the solder-substrate interface at the very beginning of the soldering process. As a result, a pronounced nucleation of IMC grains takes place during the first temperature cycle since the Ge atoms are exclusively used to form the IMCs. Once a continuous $\mathrm{Ni}_{5} \mathrm{Ge}_{3}$ layer has formed and all initially dissolved Ni has been consumed, the further consumption of $\mathrm{Ge}$ from the liquid is determined by the diffusion rate of $\mathrm{Ni}$ from the substrate through the IMC layer. The layer 
grows continuously and the solder interlayer is depleted from Ge. This leads to a pronounced change of the $\mathrm{Ge}$ concentration in the soldering gap to less than 10 at.\% and to a transformation of more than $70 \%$ of the liquid filler into Au solid solution during the first $900 \mathrm{~s}$.

Considering the microstructures presented in Figs. 9 and 10 , solidification proceeds in different directions. As shown schematically in Fig. 11, the Ni-Ge IMCs grow towards the center of the solder gap. At the same time, Au grains grow from the center of the solder gap towards the IMCs due to the depletion of Ge from the melt.

The isothermal solidification mechanism in the $\mathrm{Ni}-$ Au28Ge (at.\%) layer system differs significantly from the isothermal solidification behavior in other TLP systems. In the $\mathrm{X}-\mathrm{Sn}(\mathrm{X}=\mathrm{Cu}, \mathrm{Ag}, \mathrm{Ni}, \mathrm{Au})$ systems solidification occurs by the growth of the intermetallic phases from the interlayer-substrate interface into the liquid interlayer. The solidification rate is depending on solid state diffusion of the base material through the IMC layer to the liquid phase and the solidification front moves from the interlayersubstrate interfaces towards the centerline of the joint. Solidification is completed when the interlayer is fully converted into the IMC, and no additional phase with a higher melting point forms. In TLP bonding systems for the joining of Ni-based alloys, the melting point depressing elements diffuse into the solid Ni base material. Due to the composition change in the interlayer, its melting point increases. Solidification starts at the substrate-filler interface and proceeds towards the centerline of the joint. In this case, the solidification rate is depending on the diffusion rate of the melting point depressants in the substrate material. In comparison with these two cases, solidification in the $\mathrm{Ni-Au28Ge}$ (at.\%) system is significantly faster. The $\mathrm{Ni}-\mathrm{Ge}$ IMC growth leads directly to the formation of a $\mathrm{Au}$ solid solution. The solidification rate in the $\mathrm{Ni}-\mathrm{Au} 28 \mathrm{Ge}$ (at.\%) layer system is mainly influenced by the solid state diffusion of $\mathrm{Ni}$ through the comparably thin IMC layers

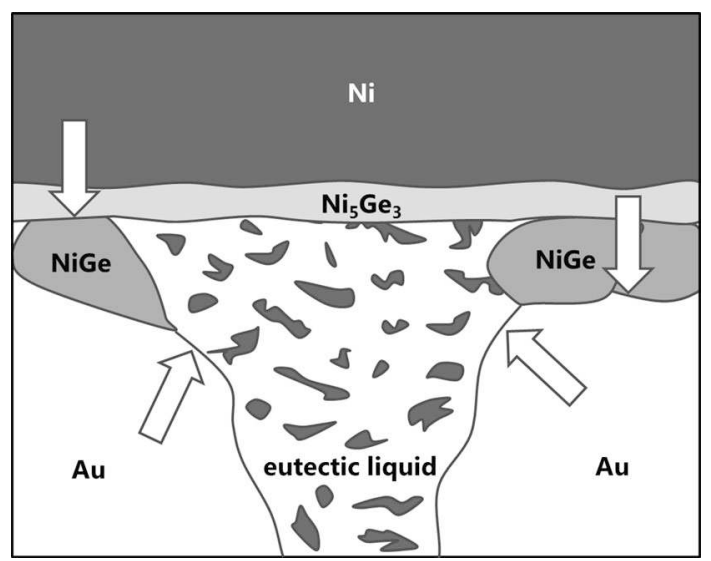

Fig. 11 Movement of solidification fronts in Ni-Au28Ge joints (the final thickness of the IMC layers is less than $20 \%$ of the overall solder gap width) as the diffusion of Ge in the remaining liquid is significantly faster.

\section{IMC growth kinetics}

In chapter 3.1 the change in Ge concentration in the liquid phase as a function of the time over liquidus was calculated (Fig. 8). Considering the mass of the solder foil of $7.6 \mathrm{mg}$ and taking into account that 28 at.\% Ge correspond to 12 wt $\% \mathrm{Ge}$, the initial amount of $\mathrm{Ge}$ in the system is $0.912 \mathrm{mg}$, corresponding to $1.256 \times 10^{-5} \mathrm{~mol}$ or approximately $7.566 \times 10^{18}$ atoms. Assuming that no $\mathrm{Ge}$ is diffusing into the substrate (cf. Data evaluation section), the difference between the number of Ge atoms after cycle $n\left(N_{\mathrm{Ge}, n}\right)$ and the initial number of $\mathrm{Ge}$ atoms $\left(N_{\mathrm{Ge}, 0}\right)$ gives the number of atoms which already reacted with $\mathrm{Ni}$ to form the Ni-Ge IMCs $\left(N_{\mathrm{Ge}, \mathrm{IMC}}\right)$ :

$N_{\mathrm{Ge}, 0}-N_{\mathrm{Ge}, \mathrm{n}}=N_{\mathrm{Ge}, \mathrm{IMC}}$

Table 1 lists some crystallographic properties of the $\mathrm{Ni}_{5} \mathrm{Ge}_{3}$ and the NiGe phase. The number of newly formed unit cells ( $n_{\text {unit cells, IMC }}$ ) for each cycle can be estimated by dividing the number of atoms consumed during the IMC formation by the number of Ge atoms per unit cell:

$N_{\mathrm{Ge}, \mathrm{IMC}} / n(\mathrm{Ge}$ atoms per unit cell $)=n_{\text {unitcells,IMC }}$

Considering the volume of the unit cells ( $\left.V_{\text {unit cell, IMC }}\right)$, the total volume occupied by the IMCs can be calculated. The thickness of the IMC layer $\left(d_{\mathrm{IMC}}\right)$ can then be estimated by dividing the total IMC volume by the area of the $\mathrm{Au}-\mathrm{Ge}$ foil $\left(A_{\text {interlayer }}\right)$ :

$N_{\text {unitcell,IMC }} \times V_{\text {unitcell,IMC }} / A_{\text {interlayer }}=d_{\text {IMC }}$

From Table 1 it can be seen that the consumption of 12 Ge atoms leads to almost the same volume growth of approximately $0.3 \mathrm{~nm}^{3}$ for both the $\mathrm{Ni}_{5} \mathrm{Ge}_{3}$ and the NiGe IMC. Since the IMC layers grow at both Ni-solder interfaces the thickness $\left(d_{\mathrm{NiGe} / \mathrm{Ni} 5 \mathrm{Ge} 3}\right)$ of the individual $\mathrm{NiGe}$ and $\mathrm{Ni}_{5} \mathrm{Ge}_{3} \mathrm{IMC}$ layers can be then calculated according to

$d_{\mathrm{IMC}} / 4=d_{\mathrm{NiGe}, \mathrm{Ni} 5 \mathrm{Ge} 3}$

Table 1 Parameter of $\mathrm{NiGe}$ and $\mathrm{Ni}_{5} \mathrm{Ge}_{3}$ unit cells

\begin{tabular}{lll}
\hline & $\mathrm{Ni}_{5} \mathrm{Ge}_{3}$ & $\mathrm{NiGe}$ \\
\hline Pearson symbol & $h P 6$ & $o P 8$ \\
Space group & $P 6_{3} / m m c$ & $P n m a$ \\
Strukturbericht designation & $B 8_{1}$ & $B 31$ \\
Structure type & $\mathrm{NiAs}$ & $\mathrm{MnP}$ \\
Atoms per unit cell & 8 & 32 \\
Ge atoms per unit cell & 4 & 12 \\
Unit cell volume $\left(\mathrm{nm}^{3}\right)$ & 0.1072 & 0.3952 \\
\hline
\end{tabular}


Figure 12 shows the resulting thickness of the IMC layers as a function of the time over liquidus. For the experimental setup without any dwell time a thickness of $1.4 \mu \mathrm{m}$ for the intermetallics was reached after the first temperature cycle. Using a dwell time of 5 and $8 \mathrm{~min}$, respectively, led to an IMC thickness of 1.6 and $1.8 \mu \mathrm{m}$ after the first cycle. It should be noted that the different dwell times at $400{ }^{\circ} \mathrm{C}$ resulted in different thicknesses for the same time over liquidus. This can be explained by the higher diffusion rate at $400{ }^{\circ} \mathrm{C}$ in comparison with the heating and cooling cycle. When all Ge is consumed a final thickness of $1.9 \mu \mathrm{m}$ can be calculated for the NiGe and $\mathrm{Ni}_{5} \mathrm{Ge}_{3}$ layers, respectively. This result is in good agreement with the microstructural investigation and final microstructure shown in Fig. 10c.

In addition, the resulting IMC thicknesses from the short-term annealing experiments and the DSC tests were combined to estimate the IMC growth rates at $400{ }^{\circ} \mathrm{C}$. The IMC thicknesses were taken directly from the SEM images. For the DSC results the IMC thickness was estimated by calculating the number of $\mathrm{Ge}$ atoms that reacted to form the IMCs during the first temperature cycle. Thus, additional points for 5 and $8 \mathrm{~min}$ at $400{ }^{\circ} \mathrm{C}$ could be obtained.

Figure 13 shows the resulting thickness for a single $\mathrm{Ni}_{5} \mathrm{Ge}_{3}$ IMC layer as a function of the square root of dwell time at $400{ }^{\circ} \mathrm{C}$. Two different regimes of the IMC growth can be distinguished: In the early state of the reaction an IMC's growth rate of $0.128 \mu \mathrm{m} \mathrm{s}^{-1 / 2}$ can be obtained from the slope of the linear interpolation line. During this first stage, the IMC layer is entirely in contact with the liquid Au28Ge (at.\%) layer. All Ni atoms diffusing through the IMC layer can react with $\mathrm{Ge}$, which allows a homogeneous and continuous growth. After approximately $300 \mathrm{~s}$, the growth rate reduced significantly to $0.004 \mu \mathrm{m} \mathrm{s}^{-1 / 2}$. In this second stage, the IMC growth is much slower because most

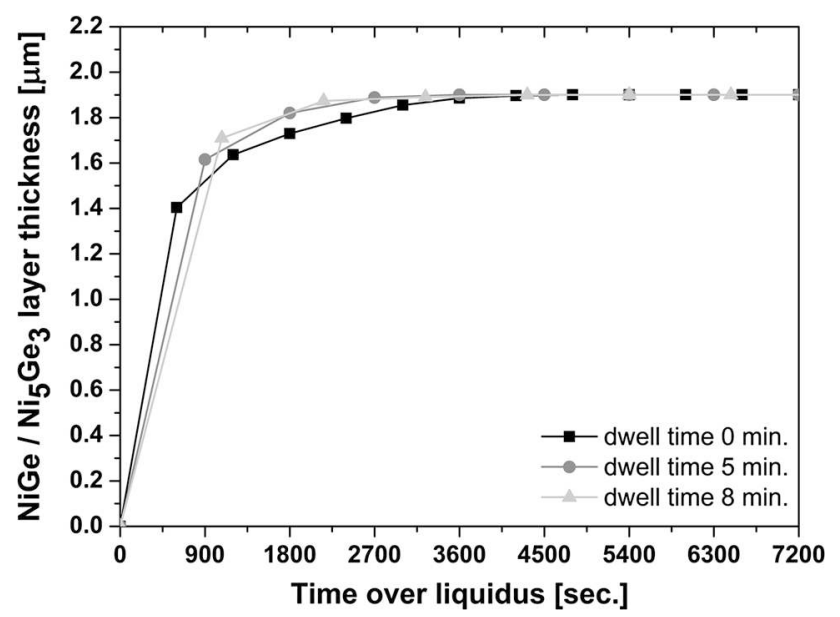

Fig. 12 Thickness of the intermetallic phases $\left(t_{\text {IMC }}\right)$ over time

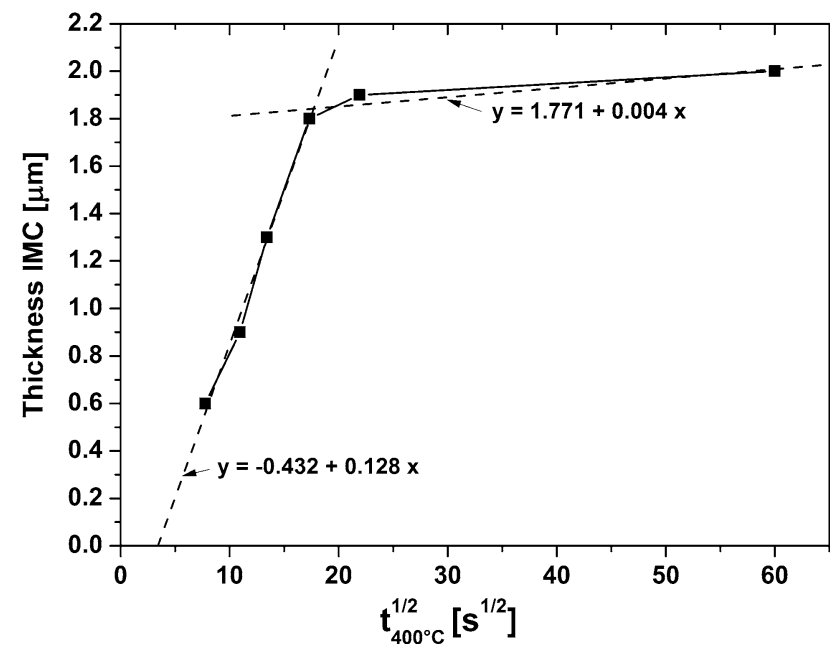

Fig. 13 IMC growth rate approximation

Ge atoms from the Au28Ge (at.\%) alloy have already been consumed and only small and discontinuously distributed eutectic areas contribute to any further IMC growth (see Fig. 10a, b). The Ge atoms diffuse laterally and the NiGe IMCs coalesce so that only a slight increase of the $\mathrm{Ni}_{5} \mathrm{Ge}_{3}$ layer can be detected.

It is interesting to note that a back-extrapolation to zero thickness in the first growth regime results in an intersection with the ordinate at $t=12 \mathrm{~s}$. It can therefore be concluded that the IMC layer does not form spontaneously after melting of the Au28Ge (at.\%) solder alloy. At the initial stage, $\mathrm{Ni}_{5} \mathrm{Ge}_{3}$ crystals nucleate at the Ni-solder interface and start to grow. The very negative enthalpy of formation of $-37 \mathrm{~kJ} \mathrm{~mol}^{-1}$ results in a high latent heat of solidification in the vicinity of the interface and dissolution of a large number of the newly formed nuclei. Only after $12 \mathrm{~s}$, the $\mathrm{Ni}_{5} \mathrm{Ge}_{3}$ crystals have reached a critical size and coalesced to a continuous IMC layer and the further growth is governed by solid state diffusion as described above.

\section{Conclusion}

In this work, the isothermal solidification process in the $\mathrm{Ni}-\mathrm{Au} 28 \mathrm{Ge}$ (at.\%) layer system was investigated by specially designed cyclic DSC tests and by short-term annealing experiments at $400{ }^{\circ} \mathrm{C}$ in combination with a microstructural analysis. It was shown that the DSC experiments enable the estimation of the time to complete solidification and the determination of the compositional change in the solder gap. By combining the results of the two experimental setups the growth rates of the IMCs were deduced and two different growth regimes could be distinguished. At first, a continuous layer of $\mathrm{Ni}_{5} \mathrm{Ge}_{3}$ forms before NiGe grains appear in the microstructure of the 
joints. The Ge depletion in the interlayer leads to the formation of solid Au grains. The remaining eutectic Au28Ge (at.\%) is confined in the volume between the Au grains and the IMC layers. The continuous consumption of the Ge and the related IMC growth on the one side and the simultaneous growth of the Au grains finally lead to complete solidification of the interlayer. The time for complete solidification at a constant temperature is depending on the diffusion rate of $\mathrm{Ni}$ in the $\mathrm{Ni}-\mathrm{Ge}$ IMC layers as well as on the overall amount of $\mathrm{Ge}$, i.e., on the interlayer thickness.

In comparison with most other TLP bonding systems, short processing times $(<1 \mathrm{~h})$ can be realized in TLP bonding using the $\mathrm{Ni}-\mathrm{Au} 28 \mathrm{Ge}$ (at.\%) interlayer system. Complete solidification of a $25 \mu \mathrm{m}$ liquid interlayer is achieved in less than $1 \mathrm{~h}$ at $400{ }^{\circ} \mathrm{C}$.

\section{References}

1. Cook GO, Sorensen CD (2011) Overview of transient liquid phase and partial transient liquid phase bonding. J Mater Sci 46:5305-5323. doi:10.1007/s10853-011-5561-1

2. Gale WF, Butts DA (2004) Transient liquid phase bonding. Sci Technol Weld Join 9:283-300

3. Lis A, Park MS, Arroyave R, Leinenbach C (2014) Early stage growth characteristics of $\mathrm{Ag}_{3} \mathrm{Sn}$ intermetallic compounds during solid-solid and solid-liquid reactions in the Ag-Sn interlayer system: experiments and simulation. J Alloy Comp 617:763-773

4. Bosco NS, Zok FM (2004) Critical interlayer thickness for transient liquid phase bonding in the $\mathrm{Cu}-\mathrm{Sn}$ system. Acta Mater 52:2965-2972

5. Bosco NS, Zok FM (2005) Strength of joints produced by transient liquid phase bonding in the $\mathrm{Cu}-\mathrm{Sn}$ system. Acta Mater 53:2019-2027

6. Li JF, Agyakwa PA, Johnson CM (2010) Kinetics of $\mathrm{Ag}_{3} \mathrm{Sn}$ growth in Ag-Sn-Ag system during transient liquid phase soldering process. Acta Mater 58:3429-3443

7. Gollas B, Albering JH, Schmut K, Pointer V, Herber R, Etzkorn J (2008) Thin layer in situ XRD of electrodeposited Ag/Sn and Ag/ In for low-temperature isothermal diffusion soldering. Intermetallics 16:962-968

8. Arafin MA, Medraj M, Turner DP, Bocher P (2007) Transient liquid phase bonding of Inconel 718 and Inconel 625 with BNi-2: modeling and experimental investigantions. Mater Sci Eng, A 447:125-133

9. Ojo OA, Richards NL, Chaturvedi MC (2004) Effect of gap size and process parameters on diffusion brazing of Inconel 738. Sci Technol Weld Join 9:532-540

10. Saha RK, Khan TI (2009) Microstructural developments in TLP bonds using thin interlayers based on Ni-B coatings. Mater Charact 60:1001-1007
11. Hong SM, Reynolds TB, Bartlow CC, Glaeser AM (2010) Rapid transient-liquid-phase bonding of $\mathrm{Al}_{2} \mathrm{O}_{3}$ with microdesigned $\mathrm{Ni} /$ $\mathrm{Nb} / \mathrm{Ni}$ interlayers. Int J Mater Res 101:133-142

12. Shalz ML, Dalgleish BJ, Tomsia AP, Cannon RM, Glaeser AM (1994) Ceramic joining II. Partial transient liquid-phase bonding of alumina via $\mathrm{Cu} / \mathrm{Ni} / \mathrm{Cu}$ multilayers. J Mater Sci 29:3678-3690. doi:10.1007/BF00356663

13. Marks RA, Sugar JD, Glaeser AM (2001) Ceramic joining IV. Effects of processing conditions on the properties of alumina joined via $\mathrm{Cu} / \mathrm{Nb} / \mathrm{Cu}$ interlayers. J Mater Sci 36:5609-5624. doi:10.1023/A:1012565600601

14. Leinenbach $\mathrm{C}$, Weyrich $\mathrm{N}$, Elsener HR, Gamez $\mathrm{G}$ (2012) $\mathrm{Al}_{2} \mathrm{O}_{3^{-}}$ $\mathrm{Al}_{2} \mathrm{O}_{3}$ and $\mathrm{Al}_{2} \mathrm{O}_{3}$-Ti solder joints - influence of ceramics metallization and thermal pretreatment on joint properties. Int $\mathrm{J}$ Appl Ceram Technol 9:751-763

15. Weyrich N, Leinenbach C (2013) Low temperature TLP bonding of $\mathrm{Al}_{2} \mathrm{O}_{3}$-ceramics using eutectic $\mathrm{Au}-(\mathrm{Ge}, \mathrm{Si})$ alloys. J Mater Sci 48:7115-7124. doi:10.1007/s10853-013-7526-z

16. Venkatraman R, Wilcox JR, Cain S (1996) Experimental study of the kinetics of transient liquid phase solidification reaction in electroplated gold-tin layers on copper. Metall Mater Trans A 28:699-706

17. Corbin SF, Lucier P (2001) Thermal analysis of isothermal solidification kinetics during transient liquid-phase sintering. Metall Mater Trans A 32:971-978

18. Kuntz ML, Corbin SF, Zhou Y (2005) Quantifying metallurgical interactions in solid/liquid diffusion couples using differential scanning calorimetry. Acta Mater 53:3071-3082

19. Kuntz ML, Zhou Y, Corbin SF (2006) A study of transient liquidphase bonding of $\mathrm{Ag}-\mathrm{Cu}$ using differential scanning calorimetry. Metall Mater Trans A 37:2493-2504

20. Kuntz ML, Panton P, Wasiur-Rahman S, Zhou Y, Corbin SF (2013) An experimental study of transient liquid phase bonding of the ternary $\mathrm{Ag}-\mathrm{Au}-\mathrm{Cu}$ system using differential scanning calorimetry. Metall Mater Trans A 8:3708-3720

21. Leinenbach C, Valenza F, Giuranno D, Elsener HR, Jin S, Novakovic $\mathrm{R}$ (2011) Wetting and soldering behavior of eutectic AuGe alloy on $\mathrm{Cu}$ and Ni substrates. J Electron Mater 40:1533-1541

22. Jin S, Duarte LI, Huang GX, Leinenbach C (2012) Experimental investigation and thermodynamic modeling of the Au-Ge-Ni system. Montashefte Chem 143:1263-1274

23. Massalski TB, Okamoto H (1990) Binary Alloy Phase Diagrams. ASM International, Ohio

24. Faupel F, Köstler C, Bierbaum K, Hehenkamp T (1988) Diffusion and vacancy-solute interaction in $\mathrm{Ni}-\mathrm{Si}, \mathrm{Ni}-\mathrm{Ge}$ and $\mathrm{Ni}-\mathrm{Sn}$ alloys. J Phys F 18:205-212

25. Rettig R, Steuer S, Singer RF (2011) Diffusion of germanium in binary and multicomponent nickel alloys. J Phase Equil Diff 32:198-205

26. Jin S, Leinenbach C, Wang J, Duarte LI, Delsante S, Borzone G, Scott A, Watson A (2012) Thermodynamic study and re-assessment of the Ge-Ni system. Calphad 38:23-34 